\title{
The Biological Diary of a Woman: Physiological Consequences of Status and Social Evaluative Threat
}

\author{
Amber R. Massey-Abernathy • Jennifer Byrd-Craven • \\ CaSandra L. Swearingen
}

Published online: 25 December 2014

(C) Springer International Publishing 2014

\begin{abstract}
Sex differences in physiological responses to social threats, as well as status seeking, have been found; however, underlying individual differences are far less documented, especially in women. Therefore, this study aimed to determine the role of self-perceived social status in response to social evaluative threat among young women. Participants completed a self-perceived social dominance questionnaire and then underwent a modified version of the Trier Social Stress Test in which they received negative feedback. Heart rate was used in order to gauge participants' physiological response. Women who rated themselves as dominant showed a reduction in heart rate from pre-task to post-task, suggesting parasympathetic activation and attunement to the social evaluative threat. Women who rated themselves as subordinate showed an increase in heart rate over the same period, suggesting sympathetic arousal and perceived threat. These findings suggest that physiological responses to social evaluative threats in women may depend on their perceived social status. The autonomic nervous system responses of dominant women may facilitate the maintenance of their social position within a hierarchy.
\end{abstract}

Keywords Social status $\cdot$ Social evaluative threat $\cdot$ Heart rate . Women

Human evolutionary history has entailed the challenges of social threats, and as such, we have developed stress response systems that are especially attuned to these threats (Flinn and Alexander 2007; Geary 2005). Life history theory asserts that physical growth, development, and reproduction are part of a life-long process of adaptive tradeoffs used for allocating

A. R. Massey-Abernathy $(\bowtie) \cdot J$. Byrd-Craven $\cdot$ C. L. Swearingen Department of Psychology, Oklahoma State University, Stillwater, OK 74078, USA

e-mail: masseya@ostatemail.okstate.edu resources (Hawley 2011; Trivers 1972). For social species like humans, many of the most important resources are social resources (Flinn 2006). Within social groups, dominance hierarchies often serve to disperse resources (Sapolsky 2004), with many of these resources being intangible like social reputation and social capital. Social hierarchies are comprised of hierarchical group-based systems of inequality (Pratto et al. 1994). Often dominant individuals take a greater share of resources, leading to a circulatory problem of hierarchies and threat of exclusion from resources.

Women's hierarchies have been shown to be more unstable than men's (Savin-Williams 1979) and therefore rejection or perceived rejection from a social group may elicit a stress response (especially for women), as it can be a significant threat to the ability to gain social resources (Stroud et al. 2009). These social dynamics may have led to sociocognitive mechanisms (i.e., reciprocal altruism) in girls and women that are more attuned to loss of social support and the nuances of same-sex hierarchies (Geary et al. 2003). For example, it was found that women were more sensitive to social cues that signaled risk of social exclusion than were men. In a related study, women had higher heart rate when reading scenarios of social exclusion, in keeping with attunement to higher risks and costs of social exclusion for women than men (Benenson et al. 2011; Benenson et al. 2013). In instances of the possibility of social exclusion, females form preventive exclusion alliances, demonstrating attuned social cognition to protection of important social resources (Benenson et al. 2011). This preparedness for the demise of a relationship has consequences for long-term stability, and female-female relationships are often observed to be less durable in response to conflict as compared to male-male relationships (Benenson and Alavi 2004). The risks of social evaluative threat and potential for social exclusion may be higher for girls and women because friendships are more dependent on equality of the give-and-take of the relationship, 
are more sensitive to personal slights (e.g., being excluded from a social event), and are less tolerant of conflict than are boys' and men's friendships (Benenson et al. 2011; Parker and Asher 1993; Rose and Asher 1999; Whitesell and Harter 1996). These differences emerge early in childhood and are maintained throughout the lifespan (Benenson et al. 2004). For women, lack of same-sex social support may also create reproductive consequences due to isolation, lack of alloparents, and this may result in increased cortisol response and health disparities (Taylor 2006).

\section{Physiological Responses to Social Evaluative Threat}

Social evaluative threat occurs when an aspect of the self (e.g., trait, ability) is or could be negatively judged by others. This threat could be a form of indirect aggression used to extend dominance hierarchies by coordinating members while simultaneously reducing overt conflicts (Ingram 2013). Evolutionary history suggests social threats that are associated with important fitness goals are also associated with physiological responses. Dickerson and Kemeny (2004) meta-analysis found that in laboratory studies, social evaluative threat was a major determinant of hypothalamic-pituitary-adrenal (HPA) axis activity and associated cortisol release. In a laboratory setting, performance situations provide conditions that require cognitive responses and have the potential for evaluation (e.g., mental arithmetic, speech task: Trier Social Stress Test; Blascovic and Mendes 2010). Recent research has shown not only HPA axis activity to be related to social evaluative threat, but the related stress response system, the autonomic nervous system, is also reactive to social evaluative threat, which is often indexed by heart rate deceleration or acceleration (Kjellberg and Magnusson 1979).

Unexpected social rejection has been associated with heart rate slowing after a rejection experience (Gunther Moor et al. 2010). Slowing of the heart rate, or deceleration periods, often reflects greater parasympathetic activity and is related to sadness, empathy, attention, or the encoding of information (De Pascalis et al. 2004; Kreibig et al. 2007; Öhman et al. 2000). Heart rate acceleration, or increase in heart rate, is often indicative of a sympathetic nervous system (SNS) response, and is associated with a perceived threat. This response has been shown to occur in the presence of a social threat, but not necessarily a physical threat. For example, during increased periods of tension from workload and academic conditions in college, first year female students showed acceleration of the heart rate (Sitdikov et al. 2001). Heart rate response, as an index of SNS response, is related to how the stressor or event is perceived. In a study involving either a rejection task or an intake of information task, participating in the rejection task resulted in heart rate acceleration while the intake of information task (which required direct attention at a sound) resulted in heart rate deceleration (Kjellberg and Magnusson 1979). The role and evolutionary benefit of an emotional response in conjunction with the stress response systems revolves around motivation to seek resources (e.g., social support) and avoid danger or loss (Nesse and Berridge 1997).

\section{Current Study}

Previous literature has shown the role of dominance hierarchies and physiological responses for men. In particular, male hierarchies have been shown to be relatively stable, though at onset of formation of male social groups or hierarchies, conflict is observed. Once the hierarchy is established, however, conflict was reduced (Pellegrini and Bartini 2001; SavinWilliams 1978). Although the hierarchy remains relatively stable overtime, there is often consistent vying for status within the hierarchy (Geary et al. 2003), with dominant or high ranking individuals having the highest level of cortisol during within-group competition but not in between-group competitions (Oxford et al. 2010). Although this work has been relevant to some social situations, little work has examined these factors in women's social interactions. Previous research has also shown that females show greater physiological reactivity to social rejection in particular (Stroud et al. 2009; Stroud et al. 2002). Due to the typical nature of female hierarchies and the value of social support, females' responses to social evaluative threat and, in particular, the role that social positioning plays in females' response have not been thoroughly examined. The need for inclusion may play a large role in creating attuned responses to social situations, in particular rejection or evaluative threat. This response is likely to differ with respect to individual differences in social standing, as it does in men. Social evaluative threat may be associated with indirect or relational aggression, and may be more often used by dominant individuals as a way of controlling social resources (Ingram 2013). The goal of the current study was to examine individual variability in autonomic nervous system (ANS) response to social evaluative threat in women as it relates to perceived social status. Rejection in the form of negative feedback was given to participants after completing the Trier Social Stress Test (TSST), an established paradigm for eliciting stress responses (Kirschbaum et al. 1993). The goal of the current study was to investigate heart rate responses in relation to self-perceived social status.

\section{Method}

Participants

Sixty-three female undergraduates participated in the study and were recruited through a subject pool website $(M$ age $=$ 
19.17). Participants were primarily Caucasian ( 70 \%). Socioeconomic status and other demographic characteristics were not assessed.

\section{Measures}

All measures and procedures were approved by the institutional review board. Participants were explained the study and asked to sign a consent form. Class work credit (for multiple classes) was given for participating in the study.

Demographic Questionnaire This survey was used to assess age, college classification, extracurricular activities, and primary social group.

Perceived Social Dominance This survey was used to measure perceived popularity of the participants within their primary social group (self-defined). We chose to focus on selfperceived social status based on previous findings showing that perception of one's experience is critical in the initiation and regulation of the stress response, more so than the objective features of events (Hellhammer and Hellhammer 2008). Participants were asked if they strongly agreed, agreed, neither agreed nor disagreed, disagreed, or strongly disagreed with five questions about their popularity standings within their primary social group. Questions included: "I am... popular, accepted, well-known, socially visible, and not popular (which was reversed scored)." Scores were centered with strongly agree given a 2 and strongly disagree given a negative 2 . A composite score of perceived social dominance was created for each participant.

Heart Rate Heart rate was taken from Omron 7 series digital blood pressure and heart rate wrist monitors (model number BP652) that were tested before the study for accuracy. Participants were informed that heart rate would be taken at three time points during the task. Each time a measurement was required, the experimenter asked participants to sit upright and position their hand and arm across their heart. Heart rate was taken from the digital wrist machines per machine instructions. Heart rate was taken shortly after participants entered the lab (time 1; approximately $5 \mathrm{~min}$ after entry), after the completion of questionnaires and the preparation for the job application speech (time 2; approximately $30 \mathrm{~min}$ later), and when the TSST and rejection was completed (time 3; approximately $20 \mathrm{~min}$ after second heart rate reading). On average, the study lasted $50 \mathrm{~min}$. Heart rate change scores were figured by subtracting the heart rate at time one from time two and time two from the heart rate at time three. Heart rate change scores were used based on previous literature demonstrating the amplitude of the stress response instead of isolated measurement (Caplan and Jones 1975; Houston 1972; Kagan et al. 1989; Massey et al. 2014; Vrana et al. 1989).

\section{Procedure}

After the consent process was completed, a female lab assistant monitored and recorded the participant's heart rate for the first time in order to get a baseline reading. Participants had been in the lab for approximately 5 min when this measure was taken. Next, participants filled out a series of questionnaires. Participants completed a demographic questionnaire and the perceived social dominance questionnaire. Once surveys were completed, the participants were administered the Trier Social Stress Test (TSST) (Kirschbaum et al. 1993). The Trier Social Stress Test is a research paradigm in which participants are asked to give a job interview or speech for $5 \mathrm{~min}$ followed by a mathematical task, which lasts $5 \mathrm{~min}$. The combination of these tasks has been found to elicit a stress response in most individuals. The TSST was slightly modified in that participants were informed they were to assume the role of a job applicant at a law firm and must deliver a 5-min speech, without notes, explaining why they are desirable to hire. They were given pen and paper and allowed $10 \mathrm{~min}$ to prepare. When the 10 min ended, participants' heart rate was measured for a second time and then participants were brought to an adjacent room. Participants were then asked to deliver their 5-min job application speech to a panel of judges, consisting of two female lab assistants. Female lab assistants were used to mimic the condition of female-female social evaluative threat. The lab assistants were trained to maintain a distant demeanor during the study and ask participant to "keep going" if they slowed or paused. All judges were blind to the social status ratings of the participants. After completion of the job application speech, the participants were asked to perform simple mental arithmetic for an additional $5 \mathrm{~min}$ (as used in the traditional TSST). The simple arithmetic involved counting backward from 1051 by subtracting 13 each time as quickly as possible. If a mistake was made, they were instructed to begin again from the beginning. This component lasted for $5 \mathrm{~min}$. After the TSST was completed, the participants were given negative feedback in order to simulate rejection. The negative feedback was in the form of four phrases given by the judges (see below). After the rejection, a third and final heart rate reading was obtained by the lab assistant. Once completed, the participants were immediately debriefed and told that the feedback they received was not, in fact, dependent on their performance. Participants were also asked not to share the specifics of the study with other individuals and were asked if they knew the actual purpose of the feedback before debriefing. None reported that they did.

The negative feedback included the following comments:

- Many of the previous participants were much more articulate than you were.

- We are surprised at the amount of times you needed to start again during the mathematical section. The other 
girls did not seem to have any trouble completing that task.

- You had many surprisingly weak points in your speech. As a college student, we were expecting a much more impressive performance.

- The other young women who have participated in this study all seem to be much more well-rounded and involved in activities on campus. We are shocked at your lack of involvement.

\section{Results}

For the perceived dominance measure, composite scores were obtained for each individual and groups of dominant (top $\sim 20 \%, n=12$ ), average (middle $\sim 60 \%, n=37$ ), and subordinate (bottom $\sim 20 \%, n=15$ ) were created. These composite scores were based on the current sample. Dominance was assessed based on participants' primary social group. Results revealed that over $95 \%$ reported their primary social group as "friends."

In order to probe the relationship between perceived dominance (using the groupings of dominant, average, and subordinate) and heart rate change (subtracting heart rate at time one from time three), an ANOVA was conducted. Heart rate scores were used in order to examine the overall stress response. By using change scores instead of a repeated measures ANOVA, the amplitude of the stress response could be observed and tested in relation to status instead of isolated measurement scores (Caplan and Jones 1975; Houston 1972; Kagan et al. 1989; Massey et al. 2014; Vrana et al. 1989). Results revealed a significant difference between dominance groups $(F$ (1, $64)=3.39, p=.048)$. A follow-up post hoc Tukey's HSD test revealed a significant difference between subordinates' and dominants' heart rate change between time one and time three (subordinates $=.50$, dominants $=-7.64, p=.044)$ (see Fig. 1). Heart rate changes from time two to three and time one to two were examined but found to not be significantly different between groups.

In addition, results revealed that heart rate at time three was significantly different between dominant and subordinate ranked individuals $(t=2.17, p=.04)$ but not between dominant and average ranked or subordinate and average ranked $(t=.57$, $p=.56 ; t=1.49, p=.14$ ) (Mean scores: $\operatorname{dom}=77.12$, ave $=$ 79.00, sub=84.86).

\section{Discussion}

The findings from this study add insight into the role status plays for women in individual variability of autonomic

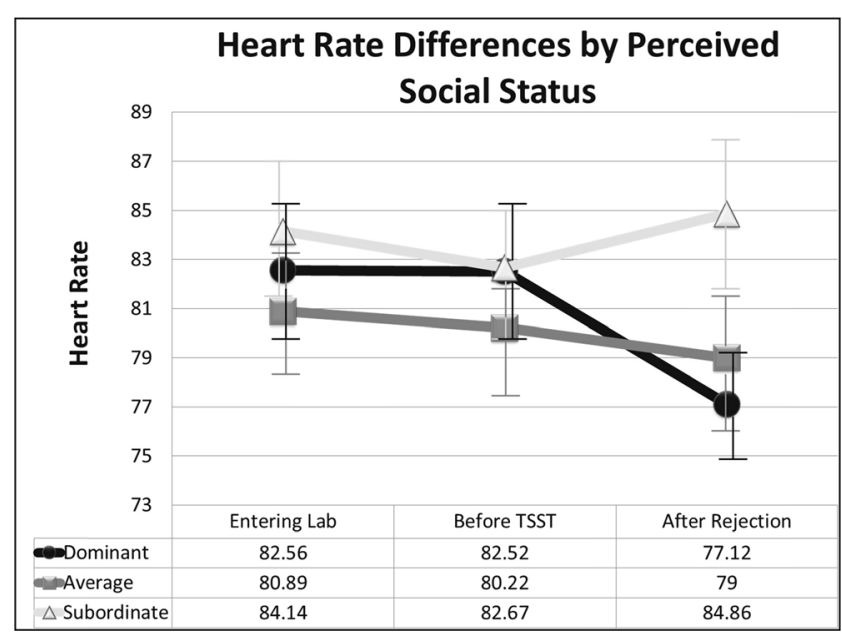

Fig. 1 The differences in heart rates as observed for different status groups. This was observed at three time points, including entering the lab (approximately $5 \mathrm{~min}$ into the study), before the Trier Social Stress Test (approximately $30 \mathrm{~min}$ later), and after rejection was experienced (approximately $20 \mathrm{~min}$ after the second heart rate reading)

nervous system response to social evaluative threat. In particular, it appears that women who perceive themselves to be dominant show a slowing of heart rate after the threat. Decreased heart rate has been associated with unexpected social threat or rejection (Gunther Moor et al. 2010), often as a reflection of sadness, empathy, attention, or intake of information (Kreibig et al. 2007; Öhman et al. 2000). Gunther Moor et al. (2013) found that heart rate slowing was largest for females who did not expect rejection. The dominant position is often associated with both stress and arousal, which may be intensified in unstable hierarchies. The unstable nature of female hierarchies may lead to greater variability in physiological responses, especially when there is potential for loss of control and negative social evaluation, as there was in this study (Dickerson and Kemeny 2004; Sapolsky 2004; SavinWilliams 1979).

These results suggest that young women who perceive themselves to be dominant within their social groups attune to the situation with greater intensity, perhaps in order to maintain their position. Physiologically, one marker of this greater attention would be slowing of the heart rate, reflecting parasympathetic activation which facilitates the processing of significant social information as well as aiding in selfregulatory adaptive and flexible behaviors (Porges 2003; Thayer et al. 2012). This may not be seen in subordinate individuals because their social position is relatively low and increasing attention to the situation may not be effective in impacting status.

Conversely, the current study also found that subordinate individuals had the largest heart rate response. Subordinate individuals may show greater heart rate in social evaluative threat because the situation may appear overwhelming. In fact, it may be the sympathetic nervous system's response that 
hinders their achievement of higher status. Without the ability to moderate the ANS response to social dynamics, they may be less emotionally regulated and less able to attune to specific features of the social environment that would allow them to avoid loss of status as a result of rejection or social threat. Animal studies show that the subordinate position is associated with chronically elevated heart rates (Eisermann 1992). However, those who manage to achieve a dominant position show lower heart rates. In humans, it was observed that anxious solitary children that were often excluded had more sustained acceleration in heart rate during a rejection experiment compared with anxious solitary children not often excluded (Gazelle and Druhen 2009). These findings are consistent with others showing that subordinate status is associated with increased heart rate and readiness to meet threats.

Recurrent selection pressures favoring attention to nuances of social stimuli and hierarchy positioning are consistent with the results of the present study and other research (Moosa and Ud-Dean 2011). Competition is often more subtle and indirect within female hierarchies, and the quest for social support and associated psychosocial and reproductive benefits have led to increased sensitivity to social rejection and associated underlying physiology that supports social cognitive attention toward these social dynamics (Geary et al. 2014). Social threats, or perceived social threats, are a common consequence of social hierarchies and appear to impact women, who are often more sensitive to social exclusion, differently from men (Stroud et al. 2002). Previous research has shown that women's heart rate response was greater than men's when reading social exclusion scenarios (Benenson et al. 2013). The current study's findings were consistent with this, and extended this literature by showing that perceived social status impacted ANS response to social evaluative threat. Although heart rate has been studied in connection with sex differences, previous studies have failed to determine if status or group importance impacted the response to social evaluative threat, especially for females. The current study expands the existing literature by showing that individual characteristics such as social positioning do in fact, impact the response.

\section{Limitations}

This study provides preliminary evidence that self-perceived social status can impact how females respond to social evaluative threat, but is not without limitations. Most notably, the study had a relatively small sample size as well as a lack of follow-up information such as recovery time of heart rate after rejection. A longer time period of study with repeated heart rate monitoring would help quantify the relationships found here. Furthermore, this study is limited by using heart rate as the sole physiological indicator of ANS response. These results do not tell us how multiple aspects of the stress response system are coordinated by hierarchy rank in response to social evaluative threat and rejection. A multi-systems investigation would yield additional insight into how the psychobiology of the stress response prepares an individual for the consequences of social threat, and how these are related to social status. In addition, studies investigating the links between social strategies, affect, rejection, social threats, and heart rate in more detail may add a clearer understanding to social positioning and the outcomes of rejection.

\section{Conclusions and Future Directions}

Numerous studies have suggested that females are more affected by social evaluative threat, rejection, and loss of social support. Studies have also shown some individual variation in response. However, the relationship between social positioning and social evaluative threats had not, to our knowledge, previously been assessed within females in particular. This study extends previous findings by showing the role young women's perceived status plays in response to social evaluative threat. The preliminary findings from the current study will inform future research aimed at determining the nuances of individual characteristics associated with psychobiological responses to social evaluative threat and associated sex differences in these responses.

\section{References}

Benenson, J. F., \& Alavi, K. (2004). Sex differences in children's investment in same-sex peers. Evolution And Human Behavior, 25(4), 258-266. doi:10.1016/j.evolhumbehav.2004.05.002.

Benenson, J. F., Duggan, V., \& Markovits, H. (2004). Sex differences in infants' attraction to group versus individual stimuli. Infant Behavior and Development, 27(2), 173-180.

Benenson, J. F., Markovits, H., Thompson, M., \& Wrangham, R. W. (2011). Under threat of social exclusion, females exclude more than males. Psychological Science, 22(4), 538-544. doi:10.1177/ 0956797611402511 .

Benenson, J., Markovits, H., Hultgren, B., Nguyen, T., Bullock, G., \& Wrangham, R. (2013). Social exclusion: more important to human females than males. Plos One, 8(2), e55851. doi:10.1371/journal. pone. 0055851 .

Blascovic, J., \& Mendes, W. B. (2010). Social psychophysiology and embodiment. In S. T. Fiske \& D. T. Gilbert (Eds.), The Handbook of Social Psychology. New York: Wiley.

Caplan, R. D., \& Jones, K. W. (1975). Effects of work load, role ambiguity, and type A personality on anxiety, depression, and heart rate. Journal of Applied Psychology, 60(6), 713-719. doi:10.1037/ 0021-9010.60.6.713.

De Pascalis, V., Strippoli, E., Riccardi, P., \& Vergari, F. (2004). Personality, event-related potential (ERP) and heart rate (HR) in emotional word processing. Personality And Individual Differences, 36(4), 873-891. doi:10.1016/S0191-8869(03)00159-4. 
Dickerson, S. S., \& Kemeny, M. E. (2004). Acute stressors and cortisol responses: a theoretical integration and synthesis of laboratory research. Psychological Bulletin, 130(3), 355-391. doi:10.1037/00332909.130.3.355.

Eisermann, K. (1992). Long-term heart rate responses to social stress in wild European rabbits: predominant effect of rank position. Physiology \& Behavior, 52, 33-36.

Flinn, M. V. (2006). Evolution and ontogeny of stress response to social challenges in the human child. Developmental Review, 26(2), 138174. doi:10.1016/j.dr.2006.02.003.

Flinn, M., \& Alexander, R. (2007). Runaway social selection in human evolution. In S. W. Gangestad \& J. A. Simpson (Eds.), The evolution of mind: fundamental questions and controversies (pp. 249-255). New York, NY US: Guilford Press.

Gazelle, H., \& Druhen, M. (2009). Anxious solitude and peer exclusion predict social helplessness, upset affect, and vagal regulation in response to behavioral rejection by a friend. Developmental Psychology, 45(4), 1077-1096. doi:10.1037/ a0016165.

Geary, D. C. (2005). The origin of mind: evolution of brain, cognition, and general intelligence. Washington: American Psychological Association. doi:10.1037/10871-000.

Geary, D. C., Byrd-Craven, J., Hoard, M. K., Vigil, J., \& Numtee, C. (2003). Evolution and development of boys' social behavior. Developmental Review, 23(4), 444-470. doi:10.1016/j.dr.2003.08. 001.

Geary, D. C., Winegard, B., \& Winegard, B. (2014). Reflections on the evolution of human Sex differences: social selection and the evolution of competition among women. In V. A. Weekes-Shackelford \& T.K. Shackelford (Eds.), Evolutionary Perspectives on Human Sexual Psychology and Behavior, 393-412. doi: 10.1007/978-14939-0314-6_20

Gunther Moor, B., Crone, E. A., \& van der Molen, M. W. (2010). The heartbrake of social rejection: heart rate deceleration in response to unexpected peer rejection. Psychological Science, 21(9), 13261333. doi:10.1177/0956797610379236.

Gunther Moor, B., Bos, M. N., Crone, E. A., \& van der Molen, M. W. (2013). Peer rejection cues induce cardiac slowing after transition into adolescence. Developmental Psychology. doi:10.1037/ a0033842.

Hawley, P. H. (2011). The evolution of adolescence and the adolescence of evolution: the coming of age of humans and the theory about the forces that made them. Journal of Research on Adolescence, 21, 307-316.

Hellhammer, D.H., \& Hellhammer, J. (eds) (2008): Stress. The brainbody connection. Key Issues in Mental Health. Basel, Karger, vol. 174, pp. $1-10$

Houston, B. K. (1972). Control over stress, locus of control, and response to stress. Journal Of Personality And Social Psychology, 21(2), 249-255. doi:10.1037/h0032328.

Ingram, G. P. (2013). From hitting to tattling to gossip: an evolutionary rationale for the development of indirect aggression. Evolutionary Psychology, 12(2), 343-363.

Kagan, J., Reznick, J. S., \& Gibbons, J. (1989). Inhibited and uninhibited types of children. Child Development, 838-845.

Kirschbaum, C., Pirke, K., \& Hellhammer, D. H. (1993). The 'Trier Social Stress Test': a tool for investigating psychobiological stress responses in a laboratory setting. Neuropsychobiology, 28(1-2), 76 81. doi: $10.1159 / 000119004$.

Kjellberg, A., \& Magnusson, E. (1979). Physiological response patterns during intake and rejection tasks. Biological Psychology, 9(1), 6376. doi:10.1016/0301-0511(79)90023-1.

Kreibig, S. D., Wilhelm, F. H., Roth, W. T., \& Gross, J. J. (2007). Cardiovascular, electrodermal, and respiratory response patterns to fear- and sadness-inducing films. Psychophysiology, 44(5), 787806. doi:10.1111/j.1469-8986.2007.00550.x.
Massey, A. R., Byrd-Craven, J., Auer, B. J., \& Swearingen, C. L. (2014). Climbing the social ladder: physiological response to social status in adolescents. Adaptive Human Behavior and Physiology. doi:10. 1007/s40750-014-0009-x.

Moosa, M. M., \& Ud-Dean, S. M. M. (2011). The role of dominance hierarchy in the evolution of social species. Journal for the Theory of Social Behaviour, 41(2), 203-208. doi:10.1111/j.1468-5914. 2010.00458.x.

Nesse, R. M., \& Berridge, K. C. (1997). Psychoactive drug use in evolutionary perspective. Science, 278(5335), 63-66. doi:10.1126/ science.278.5335.63

Öhman, A., Hamm, A., \& Hugdahl, K. (2000). Cognition and the autonomic nervous system: orienting, anticipation, and conditioning. In J. T. Cacioppo, L. G. Tassinary, \& G. G. Berntson (Eds.), Handbook of psychophysiology (2nd ed., pp. 533-575). New York, NY US: Cambridge University Press.

Oxford, J., Ponzi, D., \& Geary, D. C. (2010). Hormonal responses differ when playing violent video games against an in-group and outgroup. Evolution and Human Behavior, 31, 201-209.

Parker, J. G., \& Asher, S. R. (1993). Friendship and friendship quality in middle childhood: links with peer group acceptance and feelings of loneliness and social dissatisfaction. Developmental Psychology, 29(4), 611.

Pellegrini, A. D., \& Bartini, M. (2001). Dominance in early adolescent boys: affiliative and aggressive dimensions and possible functions. Merrill-Palmer Quarterly, 47(1), 142-163.

Porges, S. W. (2003). The Polyvagal theory: phylogenetic contributions to social behavior. Physiology \& Behavior, 79(3), 503-513. doi:10. 1016/S0031-9384(03)00156-2.

Pratto, F., Sidanius, J., Stallworth, L. M., \& Malle, B. F. (1994). Social dominance orientation: a personality variable predicting social and political attitudes. Journal of Personality and Social Psychology, 67(4), 741-763. doi:10.1037/0022-3514. 67.4.741.

Rose, A. J., \& Asher, S. R. (1999). Children's goals and strategies in response to conflicts within a friendship. Developmental Psychology, 35(1), 69.

Sapolsky, R. M. (2004). Social status and health in humans and other animals. [Article]. Annual Review of Anthropology, 33(1), 393-418. doi:10.1146/annurev.anthro.33.070203.144000.

Savin-Williams, R. C. (1978). Dominance-submission behaviors and hierarchies in young adolescents at a summer camp: Predictors, styles, and sex differences. 38.

Savin-Williams, R. C. (1979). Dominance hierarchies in groups of early adolescents. Child Development, 50, 923-935.

Sitdikov, F. G., Shaikhelislamova, M. V., \& Valeev, I. R. (2001). The effect of academic load and work conditions on the sympathoadrenal function and the indices of heart rhythm regulation in 17- to 18-year-old girls. Human Physiology, 27(5), 561-567. doi: 10.1023/A:1011908310303.

Stroud, L. R., Salovey, P., \& Epel, E. S. (2002). Sex differences in stress responses: social rejection versus achievement stress. Biological Psychiatry, 52(4), 318-327. doi:10.1016/s00063223(02)01333-1.

Stroud, L. R., Foster, E., Papandonatos, G. D., Handwerger, K., Granger, D. A., Kivlighan, K. T., \& Niaura, R. (2009). Stress response and the adolescent transition: performance versus peer rejection stressors. Development and Psychopathology, 21(1), 47-68. doi:10.1017/ S0954579409000042.

Taylor, S. E. (2006). Tend and befriend biobehavioral bases of affiliation under stress. Current Directions in Psychological Science, 15(6), 273-277.

Thayer, J. F., Åhs, F., Fredrikson, M., Sollers, J., \& Wager, T. D. (2012). A meta-analysis of heart rate variability and neuroimaging studies: 
implications for heart rate variability as a marker of stress and health. Neuroscience and Biobehavioral Reviews, 36(2), 747-756. doi:10. 1016/j.neubiorev.2011.11.009.

Trivers, R. L. (1972). Parental investment and sexual selection. In B. Campbell (Ed.), Sexual selection and the descant of man 1871-1921 (pp. 136-179). Chicago: Aldine Publishing.
Vrana, S. R., Cuthbert, B. N., \& Lang, P. J. (1989). Processing fearful and neutral sentences: memory and heart rate change. Cognition \& Emotion, 3(3), 179-195.

Whitesell, N. R., \& Harter, S. (1996). The interpersonal context of emotion: anger with close friends and classmates. Child Development, 67(4), 1345-1359. 